\title{
Levantamento revela a predominância do Lettuce mottle virus em três regiões produtoras de alface no Estado de São Paulo
}

\author{
Bruno Rossitto De Marchi ${ }^{1 *}$, David Marques de Almeida Spadotti ${ }^{1}$, Milena Leite de Oliveira ${ }^{1}$, Márcio Martinello \\ Sanches ${ }^{2}$, Renate Krause-Sakate ${ }^{1}$, Marcelo Agenor Pavan ${ }^{1}$.
}

${ }^{1}$ UNESP- Faculdade de Ciências Agronômicas, Departamento de Produção Vegetal, Setor Defesa Fitossanitária, Botucatu, SP."Bolsista CNPq/ PIBIC. ${ }^{2}$ Embrapa Recursos Genéticos e Biotecnologia.

Autor para correspondência: Renate Krause-Sakate (renatekrause@fca.unesp.br)

Data de chegada: 16/03/2012. Aceito para publicação em: 16/05/2012.

\section{RESUMO}

De Marchi, Spadotti, D.M.A.; B.R.; Sanches, M.M.; Krause-Sakate, R.; Pavan, M.A. Freqüência do LMV, LeMoV e BiMV em três regiões produtoras de alface no Estado de São Paulo. Summa Phytopathologica, v.38, n.3, p.245-247, 2012.

Entre os problemas fitossanitários da cultura da alface estão as doenças causadas por vírus. Três vírus causam sintomas de mosaico praticamente indistinguíveis: o Lettuce mosaic virus (LMV, Potyvirus), o Lettuce mottle virus (LeMoV, Sequivirus) e o Bidens mosaic virus (BiMV, Potyvirus). Através de RT-PCR utilizando-se oligonucleotídeos específicos para cada um destes vírus, amostras de alface e plantas invasoras, preferencialmente com sintoma de mosaico, foram coletadas em campos de produção de alface das regiões de Mogi das Cruzes, Campinas e Bauru no Estado de São Paulo e analisadas para a presença dos vírus. Verificou-se que o LeMoV foi o vírus encontrado com maior freqüência, seguido do LMV. A ocorrência de BiMV em alface foi extremamente baixa e restrita às regiões de Campinas e Bauru, onde também foi verificado em plantas invasoras como Bidens pilosa e Galinsoga parviflora. Esta ultima é hospedeira dos três vírus.

Palavras-chave adicionais: $\mathrm{LMV}, \mathrm{LeMoV}, \mathrm{BiMV}$

\section{ABSTRACT}

De Marchi, Spadotti, D.M.A.; B.R.; Sanches, M.M.; Krause-Sakate, R.; Pavan, M.A. Frequency of LMV, LeMoV and BiMV in three lettuce producing areas from São Paulo State. Summa Phytopathologica, v.38, n.3, p.245-247, 2012.

Among the phytosanitary problems affecting lettuce culture are the diseases caused by viruses. Three viruses cause almost indistinguishable mosaic symptoms: Lettuce mosaic virus (LMV, Potyvirus), Lettuce mottle virus (LeMoV, Sequivirus) and Bidens mosaic virus (BiMV, Potyvirus). By RT-PCR using specific primers for each virus, lettuce and weed samples, preferably with mosaic symptoms, and collected from lettuce fields in the regions of Mogi das Cruzes, Campinas and Bauru, São Paulo State, Brazil, were analyzed for the presence of these viruses. LeMoV was the most frequently found virus, followed by LMV. The occurrence of BiMV in lettuce was extremely low and restricted to the regions of Campinas and Bauru, where it was also found in weeds such as Bidens pilosa and Galinsoga parviflora. The latter plant is the host of these three viruses.

Additional keywords: LMV, LeMoV, BiMV.

A alface é infectada por diversos vírus que causam sintomas de mosaico, distorção foliar e necrose resultando em perda na qualidade do produto. Dentre esses vírus destacam-se o Lettuce mosaic virus, LMV pertencente ao gênero Potyvirus, considerado o mais importante na cultura (4), o Lettuce mottle virus, LeMoV possível membro do gênero Sequivirus e os vírus do gênero Tospovirus, causadores da doença conhecida como vira-cabeça. Além destes, o Bidens mosaic virus (BiMV), espécie tentativa no gênero Potyvirus, e o Cucumber mosaic virus (CMV, Cucumovirus) também infectam a alface (6).

Dispondo de oligonucleotídeos sensíveis e específicos para o LMV, LeMoV e BiMV, todos causadores de sintomas de mosaico muito similares, o objetivo deste trabalho foi de avaliar a ocorrência do LMV, LeMoV e do BiMV, nos campos de produção de alface de três regiões do estado de São Paulo.
Foram coletadas amostras de alface e plantas invasoras como picão-preto (Bidens pilosa) e fazendeiro (Galinsoga parviflora) preferencialmente com sintomas de mosaico, mosqueado e encarquilhamento. As coletas foram realizadas durante outubro de 2008 a abril de 2010 nas regiões de Bauru, Campinas e Mogi das Cruzes. As amostras foram identificadas por tipo e local e o RNA total foi extraído pelo método de Bertheau et al. (1). Em seguida foi realizada a amplificação dos fragmentos através de RT-PCR em uma única etapa utilizando-se os oligonucleotídeos específicos para BiMV, conforme descrito por Sanches et al. (9), LMV conforme descrito por Revers et al. (8) e LeMoV conforme descrito por Jadão (3). Para um volume de $25 \mu$ adicionaram-se: $12,5 \mu \mathrm{L}$ de PCR Master Mix 2X (Kit PCR Master Mix, Promega), $1 \mu \mathrm{M}$ de cada oligonucleotídeo, 1 unidade da transcriptase reversa AMV (Promega a 15 unidades $/ \mu \mathrm{L}$ ), 2,5 $\mu \mathrm{L}$ de RNA e água livre de RNAses 
para completar o volume de $25 \mu \mathrm{L}$. Foram retirados $5 \mu \mathrm{l}$ da reação para análise em gel de agarose $(0,9 \%)$.

Das 268 amostras analisadas de alfaces, 88 (32,8\%) estavam infectadas por um dos três vírus. Dentre essas, foram verificadas 55 positivas para o LeMoV (62,5\%) na região de Campinas, 07 $(2,61 \%)$ na região de Bauru e $08(9,1 \%)$ na região de Mogi das Cruzes. Para o LMV foram observadas 01 (1,14\%), 07 (7,95\%) e $08(9,1 \%)$ amostras positivas nas regiões de Bauru, Campinas e Mogi das Cruzes, respectivamente, enquanto que para o BiMV foram observados $01(1,14 \%)$ e $04(4,55 \%)$ amostras positivas nas regiões de Bauru e Campinas, respectivamente. Diferentemente dos resultados obtidos por Krause-Sakate et al. (5) e Firmino et al. (2) o LeMoV tornou-se mais frequente em alface quando comparado ao LMV nestes últimos anos, principalmente nas regiões de Campinas e Bauru (figura 1). No trabalho de Firmino et al. (2), das 1362 amostras analisadas, 504 estavam infectadas por LMV. Destas mesmas amostras, somente 137 estavam infectadas pelo LeMoV, e 43 destas em infecção mista com o LMV (5). Uma possível explicação para o aumento na incidência do LeMoV, seria a maior utilização nestes últimos anos de cultivares tolerantes ao LMV já que existe atualmente opções de cultivares do tipo lisa e crespa tolerantes ao LMV. O LMV pode ser dividido em dois grandes grupos, Common e Most, sendo o primeiro grupo constituído de isolados comuns que não causam sintomas em cultivares tolerantes, e o segundo grupo constituído de isolados capazes de causar sintomas em cultivares tolerantes portadoras dos genes $m o l^{1}$ e $m o l^{2}$ e, além disto, serem transmitidas pela semente nestas cultivares (4). As 17 amostras positivas de LMV sintomáticas encontradas no levantamento foram testadas para identificação do grupo utilizando-se um teste de RT-PCR específico descrito por Peypelut et. al. (7).
Somente uma amostra foi identificada como pertencente ao grupo LMV Most e as outras 16 pertencentes ao LMV Common, demonstrando que os isolados pertencentes ao LMV Common prevalecem nos campos de produção de alface, como já havia sido constatado por Firmino et al. (2) durante os anos de 2001 a 2004. Este resultado indica que mesmo com a utilização de cultivares tolerantes, ainda é baixa a pressão de seleção para que os LMV Most predominem no campo.

O BiMV foi verificado apenas nas regiões de Campinas e Bauru mostrando-se até então um vírus pouco importante em alface. Este, porém, é comumente encontrado em plantas daninhas que estão presentes em canteiros de cultivo comercial de alface. Do total de plantas daninhas infectadas, o BiMV estava presente em $23(56,1 \%)$ das amostras de Campinas e em todas as 09 amostras de Bauru (Figura 2). O BiMV ainda não foi verificado tanto em alface como em plantas invasoras da região de Mogi das Cruzes.

Galinsoga parviflora, comumente encontrada em canteiros de alface na região de Campinas, SP, foi demonstrada como hospedeira do LMV, LeMoV e BiMV. Esta já havia sido detectada como hospedeira do BiMV (9), porém não do LMV e LeMoV. Por servir como reservatório destes três vírus deve-se evitar deixá-la nos canteiros comerciais de produção de alface.

\section{AGRADECIMENTOS}

Os autores agradecem à FAPESP o auxílio concedido (processo 2007/04162-4), ao CNPq pela bolsa de iniciação científica concedida ao primeiro autor e a todos os agricultores visitados pela colaboração no trabalho. Marcelo Agenor Pavan e Renate Krause-Sakate são bolsistas do CNPq.

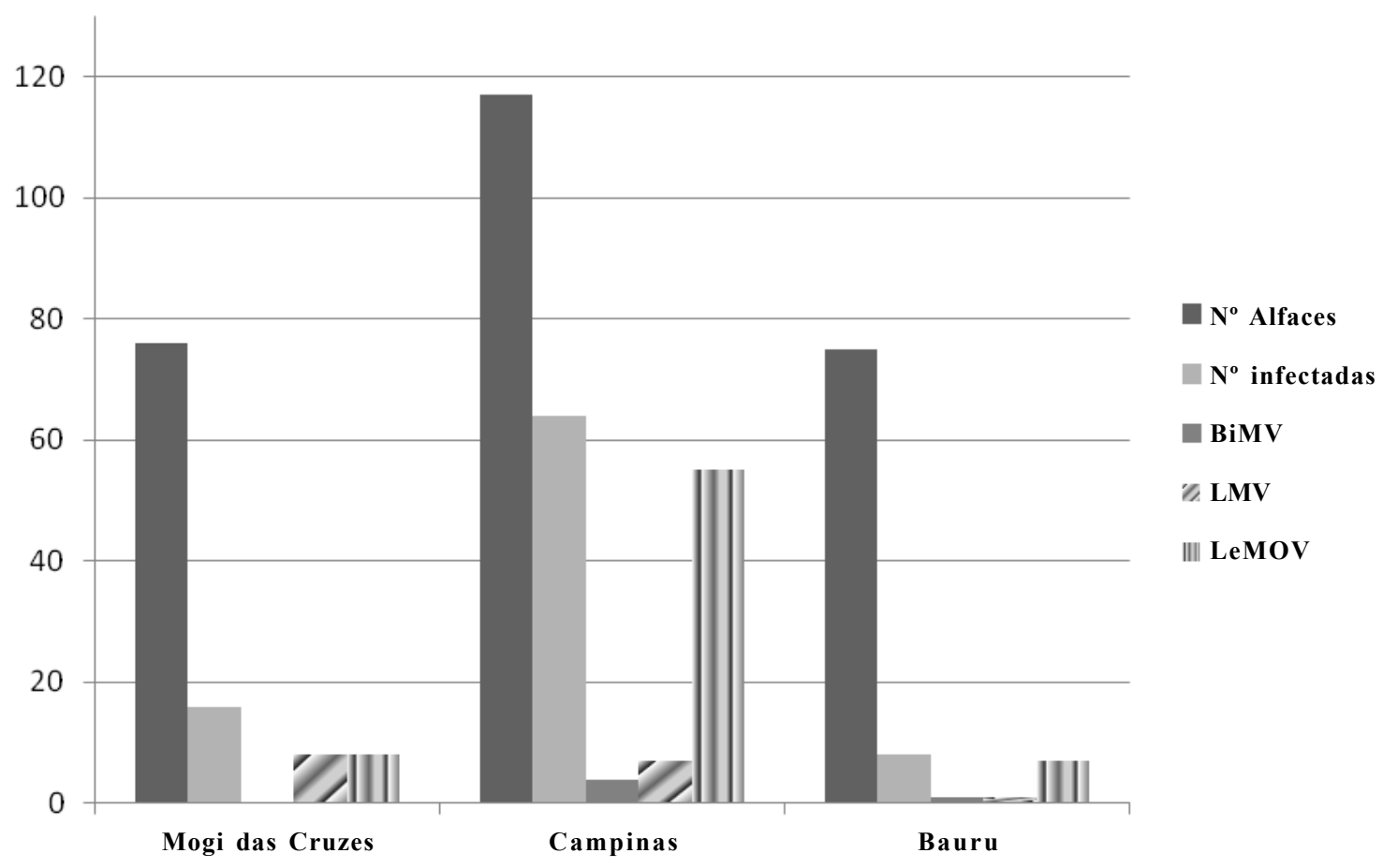

Figura 1. Número de plantas de alface coletadas em Mogi das Cruzes, Campinas e Bauru (Estado de São Paulo) e infectadas pelo Lettuce mosaic virus (LMV), Lettuce mottle virus (LeMoV) e Bidens mosaic virus (BiMV). 


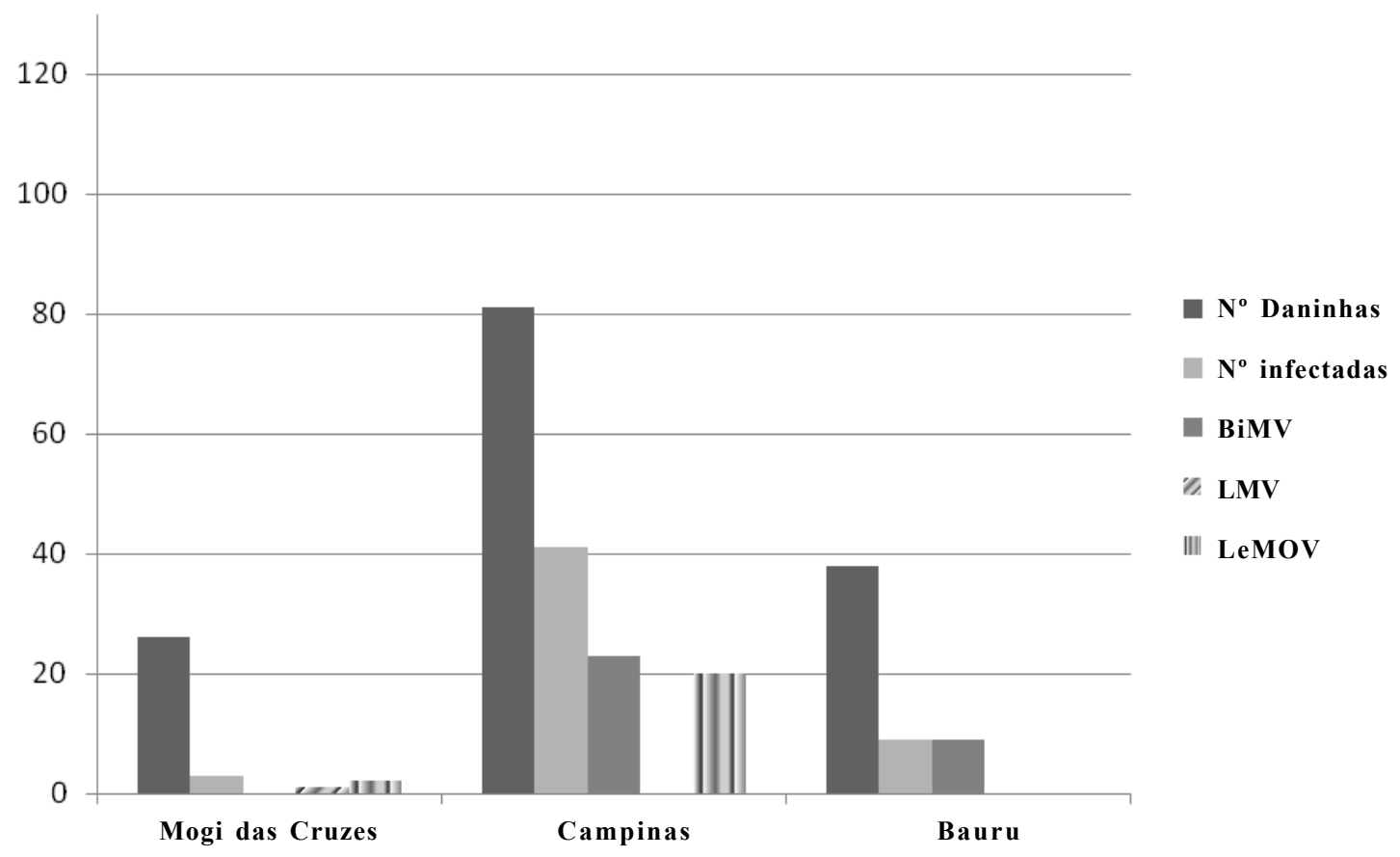

Figura 2. Número de plantas invasoras coletadas próximas aos canteiros de alface de Mogi das Cruzes, Campinas e Bauru (Estado de São Paulo) e infectadas pelo Lettuce mosaic virus (LMV), Lettuce mottle virus (LeMoV) e Bidens mosaic virus (BiMV).

\section{REFERÊNCIAS BIBLIOGRÁFICAS}

1. Bertheau, Y.; Frechon, D.; Toth, I.K.; Hyman, L.J. DNA amplification by polymerase chain reaction (PCR). In: Perombelon, M. C. M.; Van Der Wolff, J. M. Methods for the detection and quantification of Erwinia carotovora subsp. atroseptica on potatoes. Dundee: Scottish Crop Research Institute Occasional Publication, 1998.

2. Firmino, A.C.; Krause-Sakate, R.; Pavan, M.A.; Silva, N.; Hanai, S.M.; Anbo, R.H.; Nietzsche, T.; Le Gall, O. Prevalência da estirpe comum de Lettuce mosaic virus em três regiões produtoras de alface do estado de São Paulo. Summa Phytopathologica, Botucatu, v.34, n.2, p.161-163, 2008

3. Jadão, A. S. Caracterização parcial e desenvolvimento de oligonucleotídeos específicos para detecção de Sequivirus infectando alface. 2004. 126 f. Tese (Doutorado em Agronomia/Proteção de Plantas) - Faculdade de Ciências Agronômicas, Universidade Estadual Paulista, Botucatu, 2004.

4. Krause-Sakate, R.; Le Gall, O.; Fakhfakh, H.; Peypelut, M.; Marrakchi, M.; Varveri, C.; Pavan, M.A.; Souche, S.; Lot, H.; Zerbini, F.M.; Candresse, T. Molecular characterization of Lettuce mosaic virus field isolates reveals a distinct and widespread type of resistance-breaking isolate: LMV-Most. Phytopathology, St Paul, v. 92, p. 563-572, 2002.

5. Krause-Sakate, R.; Firmino, A.C.; Jadão, A.S.; Pavan, M.A.; Silva, N.; Hanai, S.M.; Anbo, R.H.; Nietzsche, T. Ocorrência generalizada do Lettuce mottle virus em três regiões produtoras de alface do Estado de São Paulo. Summa Phytopathologica, Botucatu, v.34, n.1, p.88-89, 2008.

6. Pavan, M.A.; Krause-Sakate, R.; Silva, N.; Zerbini, F.M.; Le Gall, O. Virus diseases of lettuce in Brazil. Plant Viruses, Isleworth, v. 2, p.35-41, 2008.

7. Peypelut, M.; Krause-Sakate, R.; Guiraud, T.; Pavan, M.A.; Candresse, T.; Zerbini, F.M.; Le Gall, O. Specific detection of Lettuce mosaic virus isolates belonging to the "Most" type. Journal of Virological Methods, London, v. 121, p. 119-124, 2004.

8. Revers, F.; Lot, H.; Souche, S.; Le Gall, O.; Candresse, T.; Dunez J. Biological and molecular variability of Lettuce Mosaic Virus isolates. Phytopathology, St. Paul, v. 87, p. 397-403, 1997.

9. Sanches, M. M.; Spadotti, D.M. de A.; De Marchi, B.R.; Pavan, M.A.; Krause-Sakate, R. Bidens mosaic virus: detecção via RTPCR e identificação de Galinsoga parviflora como um novo hospedeiro natural do vírus. Summa Phytopathologica, Botucatu, v.36, n.4, p.304-307, 2010. 